\title{
Classe social e produção de desigualdades: uma análise culturalista de classe ${ }^{1}$
}

\author{
Eloisio Moulin de Souza
}

\section{RESUMO}

Este artigo analisa qual a relevância de classe social como marcador social para alunos de administração e como os alunos definem classe social, utilizando-se para essa análise a abordagem culturalista de classe. Para tanto, foram aplicados questionários e conduzidos grupos focais com um roteiro semiestruturado de entrevista junto aos alunos de graduação de administração, sendo os dados produzidos investigados por meio da análise de conteúdo. Conclui-se que, apesar de autores declararem a morte de classe como marcador social, classe é um marcador social identitário no contexto estudado, produzindo hierarquias e desigualdades econômicas, culturais e sociais. Em uma análise culturalista, os alunos de administração definem classe considerando tanto aspectos objetivos quanto subjetivos, declarando a relevância de classe em sociedades menos desenvolvidas e evidenciando o alto nível de estratificação social presente na sociedade brasileira.

Palavras-chave: classe social; marcador social; desigualdades; alunos administração; abordagem cultural de classe.

\section{Social class and inequality production: a class culturalist analysis}

\section{ABSTRACT}

This article analyzes the relevance of social class as a social marker for management students and how the students define social class, using for this the culturalist analysis approach of class. In order to do so, questionnaires were carried out and focus groups were conducted with a semi-structured script of interviews among undergraduate students of management, and the data produced were analyzed through content analysis. It is concluded that, although authors declared class death as a social marker, class is a social marker of identity in the studied context, thus producing hierarchies and economic, cultural and social inequalities. In a culturalist analysis, management students define class considering both objective and subjective aspects, declaring the relevance of class in less developed societies and evidencing the high level of social stratification present in Brazilian society.

Keywords: social class; social marker; inequalities; management students; class cultural approach.

\footnotetext{
${ }^{1}$ Gostaria de agradecer aos avaliadores anônimos deste artigo pelos seus comentários e sugestões, pois os mesmos enriqueceram e contribuíram significativamente para a versão final do artigo.
}

Recebido em: 28/11/2018 Revisado em: 26/12/2018 Aprovado em: 01/04/2019

Check for updates

Eloisio Moulin de Souza (iD,

Universidade Federal do Espírito Santo, Brasil

Doutor em Psicologia, Universidade

Federal do Espírito Santo, Brasil

eloisiomoulin@gmail.com 


\section{Introdução}

Diversos autores (Safiotti, 2009; Silveira \& Nardi, 2014; Yuval-Davis, 2006) declaram que contemporaneamente existem três grandes marcadores sociais que atuam na produção subjetiva: raça, classe e gênero. Além de atuarem na produção subjetiva, esses marcadores produzem subordinação, hierarquização e exploração entre e dentro dessas categorias identitárias (Silveira \& Nardi, 2014), produzindo desigualdades (Acker, 2011). Apesar da afirmação desses autores de que classe é um marcador social, outros autores (Beck, 1992, 2000; Beck \& Beck-Gernsheim, 2002; Beck \& Lau, 2005) defendem que classe não atua contemporaneamente como um marcador social em sociedades mais desenvolvidas, declarando a morte de classe. Portanto, diante desse paradoxo, se faz necessário desenvolver estudos sobre a atuação ou não de classe como marcador social na contemporaneidade em contextos que compreendem sociedades com maior desigualdade social, como o caso brasileiro. É nesse contexto que este artigo se insere ao buscar analisar se a classe está morta ou não, ou seja, se classe atua ou não como marcador social produtor de desigualdades e, caso atue, quais são os significados de classe na contemporaneidade. No campo dos estudos organizacionais, Acker (2006) declara que a pesquisa sobre classes sociais tem seu início com a obra de Braverman (1974). Entretanto, nos estudos organizacionais contemporâneos há poucas evidências de estudos que analisam classe social (Harding, Ford, \& Fotaki, 2013; Holvino, 2010; Acker, 1999; Calás \& Smircich, 1996; Holvino, 1994, 1996; Munro, 2001). Além disso, a definição de classe não é um assunto pacífico e difere entre autores, existindo atualmente três principais abordagens: morte de classe, classe objetiva e classe subjetiva. Em sociedades economicamente mais desenvolvidas e menos estratificadas devido ao aumento dos padrões de vida, à distribuição de influência social em todas as classes, à redução de desigualdades laborais relacionadas ao gênero, ao aumento da propriedade de moradia, políticas sociais de estado, à emergência de instituições de grande escala eà expansão da educação superior de qualidade (Edlund, 2003; Evans \& Tilley, 2012), os indivíduos atribuem menor importância à atuação de classe como marcadora social e tendem a se identificar em uma classe social em termos de critérios mais subjetivos e ambíguos. Opostamente, em países menos desenvolvidos, os indivíduos tendem a dar maior importância à classe social como marcador no seu dia a dia e enxergam as fronteiras visíveis e bem delimitadas de classe atuando na classificação dos indivíduos, bem como a centralidade de classe na construção identitária e produção de desigualdades sociais (Andersen \& Curtis, 2012; Haddon, 2015).

Portanto, este artigo tem como objetivo analisar se a classe social é relevante como marcador social, bem como buscou-se verificar de e que forma os alunos matriculados no curso de graduação em administração definem classe, evidenciando os elementos objetivos e subjetivos utilizados nos processos de identificação. Desta forma, este artigo está fundamentado em uma abordagem culturalista de classe, tendo em vista que os discursos analisados estão fundamentados nas auto declarações sobre classe dos alunos, ou seja, em suas identificações subjetivas de classe e não em dados estatísticos e análises quantitativas de aspectos econômicos relacionados às 
posições de classe dos mesmos. Conforme descrito, existe uma diferença na percepção, definição e importância de classe social pelos sujeitos em função do nível de desenvolvimento econômico e acesso aos aspectos econômicos, sociais, culturais, políticos e educacionais. Nesse sentido, quanto mais desenvolvida e menos estratificada uma sociedade, mais os sujeitos tendem a valorizar aspectos subjetivos na definição de classe e menos importância dão à classe como marcador social. Entretanto, vale salientar que isso não significa que classe não atue como marcador social em sociedades mais desenvolvidas, mas apenas afirma uma menor importância atribuída à classe nesses contextos. Quanto menos desenvolvida e mais estratificada, maior a relevância de aspectos objetivos na definição de classe social e maior a utilização de classe como marcador social.

Assim, este artigo pretende contribuir com os estudos organizacionais ao abordar questões sobre classe, promovendo o debate sobre o tema e, assim, reduzir a carência contemporânea de estudos sobre classe no campo. Além disso, a abordagem culturalista de classe ainda é pouco explorada pelos estudos organizacionais brasileiros, portanto, este artigo visa trazer para o campo o debate dessa perspectiva, cobrindo também essa lacuna. Por fim, considerando que o curso de administração visa formar gestores que serão responsáveis pelo desenvolvimento de políticas públicas e privadas relacionadas à diversidade e à produção de diferenças, entender como os alunos de administração atribuem relevância à classe social e a significam é uma tarefa importante, pois permite estabelecer um diagnóstico sobre o tema, além de estabelecer direções na formação dos mesmos, para que os alunos possam ser capacitados como gestores e, assim, sensibilizados para desenvolverem políticas públicas e privadas focadas em desigualdades de classe.

Assim o próximo tópico deste artigo debate o conceito de classe social, focando principalmente na definição e diferenças entre morte de classe, classe objetiva e classe subjetiva. Em seguida, são explicados os aspectos metodológicos relacionados à pesquisa empírica realizada. Posteriormente, os dados produzidos são analisados buscando-se compreender como classe atua e é definida pelos alunos em termos objetivos e subjetivos. Por fim, são apresentadas as principais conclusões do artigo.

\section{Debatendo Classe Social}

Existem três abordagens principais de classe: morte de classe, tradicionalista (classe objetiva) e culturalista (classe subjetiva) (Bottero, 2004). Entretanto, vale de antemão ressaltar que as abordagens tradicional e cultural não eliminam aspectos objetivos e subjetivos em suas análises sobre classe. A diferença entre elas está na ênfase, importância e centralidade que cada uma dá aos elementos objetivos e subjetivos na definição e construção de classe social.

Para Spivak (1988) classe tem duas distinções: representação dentro da política econômica (classe objetiva) e representação dentro da teoria do sujeito (classe subjetiva). Sobre esse aspecto Centers (1949) foi um dos primeiros autores a distinguir a existência de aspectos objetivos e subjetivos 
relacionados à classe. Existe uma divergência entre características subjetivas, tais como estilo de vida, formas de lazer, auto posicionamento e atitudes políticas (classe), assim como os fatores objetivos renda e profissão (posição social). Em outras palavras: há antagonismos entre classe e posicionamento de classe (Haddon, 2015). Entretanto, apesar de existir um ajuste imperfeito entre classe objetiva e subjetiva, isso não significa que não exista impacto da classe na vida do indivíduo (Haddon, 2015). Além disso, os aumentos das políticas neoliberais tornam os processos de classe mais opacos e implícitos, produzindo uma relação mais complexa e ambivalente da forma com que os sujeitos se identificam em uma determinada classe social (Irwin, 2015). Assim, há práticas relacionadas à classe que estruturam a sociedade tanto objetivamente quanto subjetivamente.

Além dos aspectos objetivos e subjetivos, a meritocracia também é outra questão relevante nos estudos de classe. Em uma visão neoliberal de sujeito, todas pessoas nascem iguais e têm as mesmas oportunidades na sociedade, não existindo quaisquer desigualdades estruturais, como raça e classe, que atuariam limitando e contingenciando a mobilidade social do sujeito. Em outras palavras, a diferença entre um sujeito pobre e outro rico é apenas determinada pelo esforço individual de cada um, pois todos os sujeitos teriam as mesmas oportunidades na sociedade. Existe uma crença social de que a meritocracia é algo presente na sociedade, na qual todas as pessoas têm as mesmas oportunidades e que a meritocracia, por si só, eliminaria desigualdades sociais de classe. Essa crença faz com que as políticas de inclusão que buscam equidades de classe sejam vistas como injustas, uma vez que acredita que o sistema meritocrático funciona bem e é capaz por si só de eliminar desigualdades, bastando apenas que o indivíduo se esforce e adquira competência para conseguir romper com desigualdades que não são individuais, mas estruturais. Entretanto, esta visão de que a meritocracia por si só eliminaria desigualdades sociais relacionadas à classe recebe muitas críticas (Scully \& Blake-Beard, 2006). Primeiramente porque quem define o que é mérito são as elites que buscam valorizar as características que os fazem parecer mais apreciáveis e modelos a serem seguidos, ou seja, as elites se auto constituem como modelo e norma (Scully \& Blake-Beard, 2006). Segundo, porque o background da classe familiar de um indivíduo é o melhor preditor de quem conseguirá as melhores oportunidades na sociedade do que mérito individual, pois a posição da classe social é transmitida entre gerações onde a classe dos pais é um preditor da classe de um indivíduo (Scully \& Blake-Beard, 2006). Por fim, o valor social entre profissões diferentes em uma sociedade pode ser contestado, pois a diferença entre as altas e baixas posições laborais são também um resultado do poder exercido por aqueles que ocupam as posições mais altas, os quais acabam pagando a si mesmos rendimentos bem mais generosos (Scully \& Blake-Beard, 2006). Assim, a crença na meritocracia torna-se algo bastante promovido na sociedade por favorecer as elites com suas autobiografias produzidas para mostrar e reproduzir no imaginário social que a posição que ocupam é exclusivamente derivada de sua habilidade e competência. Devido à lógica meritocrática implantada na sociedade, as pessoas culpam a si mesmas por ocuparem uma posição de classe inferior, ao invés de atribuírem essa diferença a obstáculos estruturais que são impostos a elas (Scully \& Blake-Beard, 2006). 
Alguns autores (Bauman, 1992; Beck, 1992, 2000; Beck \& Beck-Gernsheim, 2002; Beck \& Lau, 2005) anunciaram a morte de classe social, proclamando que o conceito de classe deveria ser substituído pelo de individualização, diante do contexto de uma sociedade pós-moderna. Para eles, devido ao falecimento de identidades coletivas em sociedades reflexivas, a classe social tornou-se uma categoria zumbi, pois as sociedades ocidentais entraram em uma segunda fase da modernização, denominada de modernização reflexiva (Beck, 1992). Essa fase ocorre em função do próprio dinamismo e evolução das sociedades industriais, as quais acabaram minando os fundamentos dela própria e produzindo a dissolução de grandes categorias coletivas como classe, por exemplo. Para Beck (1992) a sociedade ocidental continua capitalista, só que um capitalismo sem classes, no qual as desigualdades não geram laços e não formam comunidades de classe. Entretanto, essa visão sobre classe social é bastante criticada, seja por autores que acreditam em uma abordagem objetiva de classe (Acker, 2006; 2011; Goldthorpe, 1996; Goldthorpe \& Marshall, 1992) ou por autores que defendem uma perspectiva subjetiva (Atkinson, 2007; Bottero, 2004, 2005; Edlund, 2003; Evans \& Tilley, 2012; Skeggs, 2004; Wasserman \& Frenkel, 2015). Portanto, classe social é uma identidade presente nas sociedades contemporâneas que interfere nas oportunidades e chances que um indivíduo terá na vida (Scully \& Blake-Beard, 2006).

A abordagem que prega a morte de classe, também denominada de pós-modernista, será descrita a seguir. Em seguida serão apresentadas e aprofundadas as definições e implicações para o estudo de classe das abordagens tradicional e cultural.

\section{A morte de classe}

Para Beck (1992, 1994, 1995), a primeira fase da modernização das sociedades ocidentais industriais capitalistas fez emergir uma segunda fase reflexiva de modernização, segunda fase esta que minou os fundamentos das sociedades industriais baseados em grandes categorias coletivas. De acordo com Beck (1995), ocorreu uma dissolução das grandes categorias de classe e em seu lugar surgiu uma individualização das desigualdades sociais e do sujeito, afirmando que identidades de classe estão mortas (Beck \& Beck-Gernsheim, 2002), o que desenvolveu uma teoria de individualização que afirma que os sujeitos foram removidos de seus status base de classe (Haddon, 2015). Nessa perspectiva, "os indivíduos foram 'desincorporados' dos modos comunais tradicionais através de políticas do welfare-state e reincorporados em novas formas pelas quais a capacidade de criar caminhos de vida e novas identidades é equivalente à reflexividade individual" (Haddon, 2015, p. 739, tradução nossa), ofertando, assim, novas possibilidades de reorganização das relações sociais. Esse fenômeno faz com que na modernidade reflexiva, também denominada de pós-modernidade por Beck e Beck-Gernsheim (2002), as pessoas sejam desincorporadas de seus compromissos coletivos, como classe, e de outras formas historicamente prescritas, para em seguida serem incorporadas em formas pelas quais as pessoas devem individualmente produzir suas próprias vidas e histórias (Atkinson, 2007). Nesse sentido, a emergência das identidades pós-modernas 
acabou erodindo o impacto de classe na constituição das subjetividades individuais (Haddon, 2015). Outros fatores históricos também contribuem para a erosão de classe e outras identidades coletivas na modernidade reflexiva. Dentre eles estão as mudanças na distribuição de renda em sociedades que promoveram o welfare-state, fazendo com que categorias consideradas âncoras na sociedade industrial tenham suas fronteiras desestabilizadas pela redução de desigualdades e acesso à educação (Atkinson, 2007). Portanto, para Beck (1997) as próprias instituições de welfare-state nas sociedades industriais ocidentais promoveram este processo de individualização, pois elas não eram focadas no interesse coletivo (Atkinson, 2007), mas em "presumir que o indivíduo seja ator, designer, malabarista e diretor do palco de sua própria biografia, identidade, redes sociais, compromissos e convicções" (Beck, 1997, p. 95). Portanto, na sociedade reflexiva, as antigas certezas, fronteiras e delimitações coletivas de classe foram derretidas no ar em favor da individualização do sujeito e de sua capacidade de agência individual. Na sociedade reflexiva os indivíduos são compelidos a construírem suas próprias biografias e identidades mediante as várias opções identitárias ofertadas e disponíveis, forçando-os trilhar individualmente por esse caminho através da sua própria capacidade de tomar decisões reflexivas. Isso os torna dependentes dos ditames do mercado de trabalho, do consumo e do sistema educativo, buscando sua autorrealização individual em produtos culturais de massa e no consumo em massa. Assim, paradoxalmente, a individuação se constitui como um fenômeno estrutural e não meramente como um fenômeno puramente subjetivo individual (Atkinson, 2007).

Desta forma, a individualização não é o fim do capitalismo, pelo contrário, ela é um fenômeno estrutural fundamentada no consumo em massa, ou seja, as sociedades ocidentais continuam capitalistas, entretanto, para Beck (1992) um capitalismo sem classes. Porém, isso não significa o fim das desigualdades sociais e da pobreza nas sociedades ocidentais industrializadas. A diferença é que as desigualdades de classe e pobreza, por exemplo, passam a ser consideradas como fases na vida média do trabalho, ao invés de uma distribuição desigual e diferenciada entre grupos (Atkinson, 2007), pois a "sociedade não pode mais olhar no espelho e ver as classes sociais. O espelho foi esmagado e tudo o que nos resta são os fragmentos individualizados" (Beck \& Willms, 2004, p. 107). Nesse sentido, para Beck e Willms (2004) os conceitos da primeira modernidade com seus grandes grupos coletivos, tais como classe, família e pleno emprego, estão mortos e não faz sentido serem estudados. Qualquer tentativa da sociologia em estudar esses grandes grupos coletivos é o mesmo que analisar categorias zumbis, pois para os autores elas não existem mais na sociedade.

\section{Abordagem tradicionalista de classe social}

A classe objetiva leva em consideração aspectos sobre renda, ocupação laboral, educação, propriedade ou não de meios de produção e até mesmo o consumo, como sendo elementos primários e centrais na definição da classe social a que um indivíduo pertence. Assim, dentro dessa lógica, elementos objetivos e materialmente mensuráveis refletem a classe à qual o indivíduo pertence (Kelley \& Evans, 1995). Comumente, a abordagem de classe que mais 
enfatiza aspectos objetivos em sua definição é a tradicionalista, fortemente influenciada pelos conceitos de Marx sobre classe social. Vale ressaltar que o estudo de classe tem como referência e ponto seminal o trabalho de Marx (1992), com sua crítica às relações dialéticas entre proletariado e capitalismo, enfatizando as relações de dominação de classe, bem como o trabalho de Weber (1978), ao afirmar que as pessoas consideram sua situação de classe como um status de grupo.

Desta forma, condições socioeconômicas atuam na construção da identidade produzindo diferenças marcantes entre indivíduos de classes sociais diferentes (Sales, 2014). Divisões de classe são fundamentadas em processos econômicos de produção e consumo (Yuval-Davis, 2006), nos quais as identidades sociais são construídas nas relações com a posição econômica do indivíduo na sociedade. Classe é entendida como explicita, forma de exploração, coletiva e luta oposicional (capitalistas versus proletariado), ou seja, classe é definida como sendo um grupo coletivamente coeso por meio da consciência de classe, em que a classe é sempre algo oposicional, categórico e coletivo (Bottero, 2004). Classe define a assimetria de poder e as formas de controle dos meios de subsistência na sociedade (Acker, 2011), fazendo com que a classe seja definida sempre como marcador de desigualdade e diferença, em que a expressão igualdade de classes seria um oximoro.

Sendo algo oposicional, classe sempre está em constante luta. Para que isso ocorra, as classes devem ser delimitadas e separadas por fronteiras claramente estabelecidas que definem quem são os dominantes, os dominados e os explorados. Assim, com a existência dessa fronteira clara e bem delimitada, os indivíduos conseguem desenvolver claramente consciência de classe e, consequentemente, podem se identificar facilmente em uma classe, sendo que a possível falta de identidades de classe manifestaria exatamente a própria exploração e conflito de classes na produção de uma falsa consciência (Bottero, 2004). Assim, a identidade de classe em um determinado grupo determina a consciência e ação dos indivíduos.

Portanto, a abordagem tradicional enfatiza os aspectos orientados à análise do conflito de classes, fundamentada em modelos categóricos pelos quais cada pessoa possa ser classificada em uma única classe. Essa abordagem é também denominada de objetiva, pois usa dados relacionados às ocupações laborais, educação e renda para definir com exatidão a classe que um indivíduo pertence (Ekehammar, Sidanius, \& Nilsson, 1987). Um exemplo dessa concepção de classe encontra-se presente na busca pela adoção de um conceito de classe cada vez mais preciso, manifesto nos trabalhos de Goldthorpe (1996) e Goldthorpe e Marshall (1992), os quais procuram construir um modelo objetivo para a análise de classe social, fundamentando-se na atividade laboral exercida pelo indivíduo. Entretanto, os culturalistas criticam esse modelo por limitar o conceito de classe a atividades laborais e econômicas, não abordando aspectos cultuais e sociais exercidos pelo indivíduo que estão para além do econômico e que também interferem na construção da identidade de classe, tais como relações entre classe e consumo cultural (Savage et al., 2013). Assim sendo, dando continuidade a este debate, o próximo tópico discutirá a abordagem culturalista de classe. 


\section{Abordagem culturalista de classe social}

Para os culturalistas (Atkinson, 2007; Bottero, 2004, 2005; Edlund, 2003; Evans \& Tilley, 2012; Skeggs, 2004; Wasserman \& Frenkel, 2015) classe é uma forma específica de estruturação das desigualdades sociais, envolvida em aspectos históricos, sociais, econômicos e políticos específicos. A abordagem culturalista de classe expande o conceito de classe ao incluir aspectos sociais e culturais em sua análise, considerando o modelo tradicionalista causal, determinístico e fundamentado no econômico. Assim, a abordagem cultural critica a crença dos objetivistas na existência prévia de identidades de classes coesas ou de grupos distintos bem delimitados, valorizando a diferenciação hierárquica individualizada, ao invés da diferenciação coletiva (Bottero, 2004). Assim, culturalistas (Bottero, 2004, 2005; Crompton, 1996; Devine, 2004; Savage, 2000; Savage et al. 2013) expandem o conceito de classe para além do econômico, contudo, sem abandonar o econômico.

Os culturalistas defendem uma ressignificação de classe social para que seu conceito seja mais abrangente e profundo (Bottero, 2004; Crompton, 1996), buscando entender as interseccionalidades entre o econômico, o social e o cultural. Desta forma, defendem um conceito de classe multifacetado e plural, no qual a classe é entendida como um "conceito de organizing para a investigação de uma ampla gama de questões associadas à desigualdade social e à diferenciação social" (Crompton, 1998, p. 208, tradução nossa). O organizing é definido por Law (1992, p. 382, tradução nossa) como um processo heterogêneo pelo qual "fragmentos e pedaços do social, do técnico, do conceitual e do textual são encaixados e então convertidos (ou 'traduzidos') em um conjunto de produtos científicos igualmente heterogêneos". Assim, o organizing busca analisar o processo, ou seja, explorar e descrever "processos locais de padronização, orquestração social, ordenação e resistência" (Law, 1992, p. 387, tradução nossa). Ao invés de conceituar classe como significando identidades e grupos coletivamente coesos, homogêneos, essenciais e distintos (Bottero, 2004), buscam entender como processos culturais são envolvidos por práticas sociais e econômicas (Devine \& Savage, 2000). Em outras palavras, os culturalistas consideram aspectos sociais e culturais nos micro processos "pelos quais classes são criadas e sustentadas ao longo do tempo e espaço" (Devine, 1998, p. 33, tradução nossa).

Portanto, ao invés de classe significar um grupo econômico coletivamente coeso, objetivamente explícito e homogêneo, classe é entendida como cultural, individualizada, subjetiva, multifacetada e implícita. Classe é concebida como uma hierarquia individualizada que rompe com as categorias objetivas fundamentais de classe (Bottero, 2004). Portanto, ao unir aspectos culturais, econômicos e sociais na teorização de classe, culturalistas reconhecem que não é necessária a existência e formação de identidades de classe explícitas, homogêneas e distintas para que classe atue como um princípio ordenador do social. Apesar dos indivíduos não mais se reconhecem explicitamente em identidades de classe que representem grupos discretos, objetivos e distintos, o processo de classe existe e continua atuando na produção de hierarquias sociais e identidades (Bottero, 2004). 
As pessoas se identificam em classes por meio de comparações relacionais com indivíduos de outras classes, mas esta comparação produz identidades coletivas fracas ao invés de identificações coletivas de classe coesas e homogêneas. Esse processo de produção de identidades fragmentadas de classe é denominado de desidentificação (Bottero, 2004). Assim, a falha na produção de identidades de classe coesas é uma questão a ser abordada pela abordagem cultural; entretanto, a produção de identidades não coesas não significa que os processos de classe são falhos e que não existam. Pelo contrário, a própria desidentificação é um resultado dos processos de classe (Bottero, 2004). A desidentificação não declara a morte dos processos de classe e das identidades de classe, mas declara o falecimento do significado coletivo coeso de classe. Enquanto na abordagem tradicional classe é explicita, categórica, oposicional e coletiva, na abordagem cultural a classe é implícita, relacional, hierárquica e individualizada, em que a própria natureza múltipla e nivelada das hierarquias obscurece fronteiras entre classes (Bottero, 2004).

A desidentificação declara que classe não é algo tão claro, transparente, objetivo e explícito para o indivíduo, pois atua de forma implícita e subjetiva. Entretanto, classe ainda é importante e continua a moldar no dia a dia as atitudes e ações das pessoas (Reay, 1998), afinal, apesar das identidades coletivas produzidas serem fracas, as pessoas ainda continuam a definir suas identidades por meio de comparações que fazem com membros de várias classes sociais, gerando identidades de classe mais implícitas ainda. Classe continua a formar a identidade social das pessoas, mas de uma forma altamente individualizada, na qual classe e cultura são vistos como formas de diferenciação, ao invés de formas de identidades coletivas (Savage, 2000), o que possibilitaria compreender como as desigualdades funcionam e operam, salientando que a percepção das desigualdades é subjetiva (Bottero, 2004).

Desigualdades subjetivas são percebidas pelos indivíduos por meio de comparações que eles fazem com outros indivíduos, produzindo sentidos de sua própria posição social. Desta forma, nesse processo de comparação é relevante a qualidade das informações disponíveis aos indivíduos que facilitam, ou não, as comparações realizadas nas/pelas práticas cotidianas. Neste sentido, desigualdade é um conceito relacional cuja percepção depende da análise das vantagens de diferentes grupos ou indivíduos, na qual para que um indivíduo possa estabelecer sua posição social se faz necessário que o mesmo seja capaz de estabelecer sua posição em relação aos outros que lhe são próximos (Bottero, 2012; Marshall \& Swift, 1996; Runciman, 1966).

Além disso, quando questionados diretamente sobre sua classe social, os indivíduos interpretam o significado de classe de diversas formas: estilo de vida, moradia, aspirações, educação, aristocracia, superioridade, respeito, recursos financeiros, demografia, vizinhança, tamanho da residência, atividade laboral exercida, consumo, propriedade e desigualdades (Bottero, 2012). Classe é um conceito tão multifacetado que as pessoas tendem a se classificar em função de background familiar, renda, ocupação, relacionamento com seu superior hierárquico, educação, qualificações e inclusive integridade moral. Assim, classe é produzida em termos de 
múltiplos elementos, revelando a dificuldade dos sujeitos em se encaixarem e encapsularem suas experiências e percepções diárias (Irwin, 2015).

Ao se comparar com outros membros da sociedade em termos de classe, as pessoas tendem a utilizar muitas vezes como base para esta comparação o estilo de consumo ao invés do tipo de trabalho e nível de renda (Runciman, 1966), sendo que em termos de desigualdades subjetivas as pessoas estão mais inclinadas a se classificarem como se estivessem no meio (classe média), pois consideram que o seu estilo de vida e os das pessoas próximas não são muito diferentes (Bottero, 2012; Evans \& Kelley, 2004; Irwin, 2015). Contemporaneamente, as declarações que os indivíduos fazem de si mesmos em termos de classe são altamente complexas e não coincidem exatamente com a classe objetiva a que pertencem, na qual a classe não pode ser considerada como uma fonte monolítica de identidade, mas algo atravessado e cortado por múltiplos aspectos.

Assim, categorias de classes estão perdendo sua distinção em relação às outras categorias e a estrutura de classe está cada vez mais fragmentada por múltiplas influências, fazendo com que, por exemplo, a classe trabalhadora perca sua coesão social e distinção (Evans \& Tilley, 2012). Portanto, ao invés de tratar classe como um aspecto objetivo, a abordagem cultural enfatiza as percepções individuais que um indivíduo tem de sua classe social, sendo considerada uma abordagem subjetiva (Ekehammar, Sidanius, \& Nilsson, 1987). Essa abordagem multidimensional afirma que classe não é um fenômeno meramente econômico, mas multifacetado e profundamente interligado com formas de reprodução social e diferenciação cultural (Savage et al., 2013; Devine, 2004; Haddon, 2015; Irwin, 2015).

\section{Método}

Este artigo é resultado de uma pesquisa qualitativa mais ampla sobre o impacto das políticas de cotas na construção da identidade e inclusão de estudantes de graduação em administração. Assim, os sujeitos de pesquisa são estudantes de graduação em administração de uma universidade federal brasileira, localizada na região sudeste, que estão matriculados entre o primeiro e terceiro semestres. A universidade pesquisada tem políticas de cota social destinadas a estudantes pobres. Os sujeitos de pesquisa foram alunos matriculados entre o primeiro e terceiro semestres, pois a discussão de aspectos de classe são debatidos por eles mesmo antes de ingressarem na universidade, desde o ensino médio quando os mesmos já discutem e decidem se irão optar por cotas sociais ou não. Ademais, também nos primeiros semestres da universidade são analisadas se as questões sobre classe estão presentes no dia a dia dos estudantes de graduação e se são abordados nas disciplinas. Foram pesquisados alunos cotistas e não cotistas, sendo que a classe social a que pertencem foi obtida por auto declaração dos mesmos, conforme Tabela 1. 
Tabela 1 - Auto Declaração de Classe Social Alunos Entrevistados

\begin{tabular}{cccc}
\hline Nome & Classe & Nome & Classe \\
\hline E1 & Média & E20 & Média \\
E2 & Média & E21 & Média \\
E3 & Média & E22 & Média Baixa \\
E4 & Média & E23 & Média Baixa \\
E5 & Média & E24 & Média \\
E6 & Média Baixa & E25 & Média \\
E7 & Média Baixa & E26 & Classe Baixa \\
E8 & Pobre & E27 & Média Baixa \\
E9 & Média & E28 & Média \\
E10 & Média & E29 & Média \\
E11 & Pobre & E30 & Média \\
E12 & Média & E31 & Média \\
E13 & Média & E32 & Média \\
E14 & Média & E33 & Média \\
E15 & Média Baixa & E34 & Média Baixa \\
E16 & Média Baixa & E35 & Média \\
E17 & Média & E36 & Média \\
E18 & Média Baixa & E37 & Média Baixa \\
E19 & Média & E38 & Média \\
\hline
\end{tabular}

Fonte: Autor Artigo

A produção de dados junto aos alunos foi efetuada em duas etapas: (1) aplicação de questionário e (2) grupos focais com roteiro semiestruturado. O principal objetivo do questionário foi proporcionar um primeiro contato com o fenômeno estudado para, a partir dos dados obtidos, ter-se claramente uma visão geral sobre classe na perspectiva dos alunos. O questionário foi estruturado em dois blocos, um com perguntas demográficas e outro com questões relacionadas às cotas sociais. Assim, aplicou-se o questionário o que possibilitou 148 questionários respondidos. Os dados produzidos na aplicação dos questionários foram tabulados e tratados estatisticamente. A partir das respostas dos alunos às questões previamente elaboradas, os principais pontos que deveriam ser melhor explorados foram identificados e aprofundados na segunda etapa da produção de dados. A segunda etapa de produção de dados foi realizada por meio de 6 grupos focais com roteiro semiestruturado com 38 alunos que responderam aos questionários. Inicialmente convidou-se todos os alunos que responderam os questionários para participarem dos grupos focais. Sendo assim, 38 alunos se disponibilizaram a participar dos grupos focais. Os alunos foram organizados em seis grupos focais, nos quais foi solicitado que os alunos respondessem às perguntas colocadas para o grupo. O roteiro semiestruturado dos grupos focais continha 30 perguntas estruturadas e organizadas em 4 blocos, assim descritos: (1) motivos pela escolha do curso de administração; 
(2) auto declaração de classe e os sentidos de classe social; (3) Intersecções de classe social e (4) políticas de cota e classe social. Para preservar o anonimato dos alunos entrevistados, eles foram denominados pela letra $E$, seguida de numeração, variando de E1 até E38, conforme consta na Tabela 1. Considerando que este artigo está fundamentado na abordagem cultural de classe subjetiva, a classe social dos mesmos foi obtida por autodeclaração de classe social durante os grupos focais. Por fim, os dados produzidos durante a realização dos grupos focais foram gravados e posteriormente transcritos.

Após a produção e transcrição de dados, os mesmos foram analisados sob a ótica da abordagem cultural de classe, por meio de análise de conteúdo, compreendida como um conjunto de técnicas que tem como intuito analisar os dados produzidos através da sistematização de procedimentos objetivos, possibilitando a inferência de conhecimentos relativos aos dados produzidos (Bardin, 2009). Essa investigação compreendeu a análise dos dados produzidos em categorias mistas, determinadas mediante o objetivo de pesquisa. Assim, foram estabelecidas três (3) categorias, sendo elas: (1) classe social - um marcador social; (2) critérios objetivos - o socioeconômico em evidência e (3) classe subjetiva - uma perspectiva multifacetada. A primeira categoria foi elaborada à priori e abarca a atuação ou não de classe social como marcador social. As outras duas categorias foram elaboradas a partir das respostas dos alunos de acordo com os sentidos subjetivos de classe produzidos pelos mesmos. A seguir, são apresentados os resultados desse processo de análise do conteúdo.

\section{Classe Social: um marcador social}

Apesar de alguns autores declararem a morte contemporânea do conceito de classe social (Bauman, 1992; Beck, 1992, 2000; Beck e Beck-Gernsheim, 2002; Beck e Lau, 2005), chegando ao ponto de afirmarem que vivemos em uma sociedade capitalista sem classes (Beck, 1992), os alunos de administração reconhecem a importância e a existência de classe social na sociedade brasileira e sua atuação como marcador social relevante para distinguir e hierarquizar pessoas e grupos, usando para isso elementos objetivos e subjetivos para a definição de classe, conforme demonstram os discursos analisados a seguir. Para eles, classes sociais "São categorias para diferenciar as pessoas que têm e as pessoas que não têm e precisam daquilo das pessoas que têm" (E8, Pobre). Portanto, classe existe no contexto brasileiro e, conforme E8 declara, ainda atua produzindo "a contínua e sistemática diferença no acesso e controle de recursos para provisionamento e sobrevivência” (Acker, 2006, p. 444).

Portanto, os alunos atribuem uma grande importância à classe social nas práticas contemporâneas, visualizando as fronteiras e classificações, mesmo que turvas, que classe produz, demonstrando a importância do conceito de classe em sociedades economicamente e socialmente estratificadas (Andersen \& Curtis, 2012; Haddon, 2015), pois "Classe social define as pessoas dentro da sociedade. É para diferenciar mesmo" (E10, Média). Ademais, "Falar de classe é segregar!" (E21, Média). Assim, conforme 
afirmam os discursos de E8; E10 e E21, classe atua no contexto brasileiro como produtor de diferença, segregação e assimetria de poder (Acker, 2011), demonstrando que no Brasil classe ainda é um marcador de desigualdade e produtor de diferenças que interfere diretamente nas oportunidades e chances que a pessoas terão em suas vidas (Scully \& Blake-Beard, 2006).

\footnotetext{
Aquilo que eu aprendi sobre definição de classe social é a definição que faz distinção da renda familiar. É ela que vai te classificar na classe A, B, $\mathrm{C}$, D e E. [...] Mas eu concordo com o que eles falaram que tem essa questão da segregação, de preconceito (E24, Média).
}

A afirmação "isso [classe] segrega" (E23, Média Baixa) é constatada repetitivamente pelos alunos, declarando a relevância de classe como marcador social na sociedade brasileira e, consequentemente, sua importância na produção subjetiva (Safiotti, 2009; Silveira \& Nardi, 2014; Yuval-Davis, 2006). De modo a buscar compreender a atuação de classe social na formação subjetiva, o próximo tópico deste artigo destina-se exatamente a analisar os significados de classe social segundo os alunos de administração dentro da política econômica e na representação na teoria do sujeito (Spivak, 1988). Quando analisamos classe tendo-se como referência a política econômica, estamos considerando os aspectos objetivos de classe, ou seja, classe objetiva. Já quando consideramos nessa análise aspectos subjetivos, estamos nos referindo à classe subjetiva (Centers, 1949). Portanto, existe uma diferença entre classe (classe subjetiva) e posicionamento de classe (classe objetiva) (Haddon, 2015).

Durante a realização das entrevistas, ao serem perguntados como definiriam classe social, alunos a definiram de acordo com critérios objetivos e subjetivos. Entretanto, vale destacar que apesar dos alunos utilizarem critérios objetivos para a definição de classe, isso não torna essa definição uma abordagem tradicional de classe, tendo em vista que tal definição está fundamentada em aspectos históricos, sociais e econômicos específicos pelos quais os alunos se identificam subjetivamente e utilizam essa identificação com elementos econômicos para significar classe para eles próprios. Além do mais, ao mesmo tempo os alunos demonstraram que classe não é um conceito determinado pelo econômico, levando outros aspectos na definição de classe em consideração. Portanto, o tópico a seguir sobre critérios objetivos, no qual aspectos socioeconômicos são salientados pelos alunos, não é sinônimo de classe objetiva, conforme concebida pelos tradicionalistas. Desta forma, as análises a seguir de como os alunos de administração definem classe social estão organizadas entre estes dois critérios de classe: objetivos e subjetivos.

\section{Critérios objetivos: o socioeconômico em evidência}

A classe objetiva utiliza elementos mensuráveis para definir e estabelecer as classes sociais existentes (Kelley \& Evans, 1995) como: renda, ocupação laboral, escolaridade, consumo e propriedade (Ekehammar, Sidanius \& Nilsson, 1987; Goldthorpe, 1996; Goldthorpe \& Marshall, 1992; Yuval-Davis, 2006). Dentro dessa lógica, a classe social que um indivíduo pertenceria pode ser materialmente medida através de aspectos objetivos que materialmente estabeleceriam qual classe o indivíduo pertence sem qualquer problema 
de identificação (Kelley \& Evans, 1995), acreditando que a centralidade no econômico define a existência de fronteiras bem delimitadas entre identidades de grupos sociais que seriam distintos e coesos entre si. Conforme será analisado a seguir, os alunos utilizam esses critérios econômicos para significarem classe, corroborando com o que os autores culturalistas afirmam, ao declararem que a abordagem subjetiva não é um abandono do econômico (Bottero, 2004, 2005; Crompton, 1996; Devine, 2004; Savage, 2000; Savage et al. 2013), mas uma expansão para além do econômico.

No caso brasileiro, o Instituto Brasileiro de Geografia e Estatística (IBGE) utiliza até os dias de hoje a renda familiar como critério definidor da classe social objetiva, classificando as pessoas em cinco classes sociais de acordo com a renda familiar das mesmas: classe $\mathrm{E}$ (renda familiar até 2 salários mínimos); Classe D (renda entre 2 e 4 salários mínimos); Classe C (renda entre 4 e 10 salários mínimos); Classe B (renda entre 10 e 20 salários mínimos) e Classe A (renda acima de 20 salários mínimos). Assim, em função dessa classificação objetiva estabelecida pelo IBGE, os 158 alunos de administração que responderam o questionário aplicado tiveram que assinalar qual classe social pertenceriam de acordo com o critério definido pelo IBGE. Desta forma, 7,5\% declararam pertencer a Classe E; 20,3\% a Classe D; 51,9\% a Classe C; $8,3 \%$ a Classe B e 12\% a Classe A. Portanto, $72,2 \%$ dos alunos declararam pertencer objetivamente às classes $\mathrm{D}$ e $\mathrm{C}$, sendo que existem mais alunos que pertencem as classes $\mathrm{B}$ e $\mathrm{A}$ do que a classe $\mathrm{E}$.

Entretanto, os alunos não se identificam nessas categorias de classe estabelecidas pelo IBGE. Apesar de utilizarem critérios econômicos nas definições de classe quando solicitados para se auto identificarem em termos de classe, os alunos estabelecem denominações e categorias de classe diferentes das empregadas pelo IBGE, demonstrando como critérios considerados meramente objetivos são subjetivamente ressignificados pelos alunos no processo cultural de definição de classe. As respostas surgidas durante a execução das entrevistas de classe, sendo consideradas como um aspecto objetivo, manifestam que os alunos entendem classe social como "Diferenciação econômica entre pessoas" (E34, Média Baixa). Neste processo de diferenciação econômica, o local onde reside e o consumo de determinados bens também são aspectos considerados pelos alunos como relevantes na definição de classe: "O local onde eu vivo também. E também tudo que eu tenho: computador, celular, o que me faz ser classe média" (E36, Média). E9 (Média) também acredita nos elementos puramente econômicos como definidores da classe social de um sujeito e acrescenta aos aspectos anteriormente enunciados pelos alunos o nível de escolaridade como forma de definição objetiva de classe social.

\begin{abstract}
A instrução, a escola também, acho que isso define a classe social também. [..] a questão do [custo do] metro da moradia [...] onde você trabalha e o quanto você ganha, quantas pessoas você tem na sua família, não adianta você ganhar $\mathrm{R} \$ 2.000,00$ e ter cinco pessoas na sua família que acaba que não dá para todo mundo né. (E9, Média)
\end{abstract}

Assim, escolaridade, local de moradia, ocupação laboral e renda familiar são elementos objetivos definidores da classe social, mas que adquirem inteligibilidade por meio de processos culturais e sociais. 
Conforme já dito, a medição da classe objetiva pode ser fundamentada na utilização de critérios econômicos como cargo/ocupação laboral que a pessoa exerce, pois cada cargo/ocupação laboral irá refletir na renda recebida pelo indivíduo, por isso a atividade laboral é o critério utilizado pelo modelo Nuffield ou Goldthorpe de medição de classe social (Goldthorpe, 1996; Goldthorpe \& Marshall, 1992). Ekehammar, Sidanius e Nilsson (1987) acrescentam à atividade laboral elementos ligados à educação para definirem com maior exatidão a classe objetiva de um indivíduo. Assim, E9 considera relevante a utilização de todos esses elementos presentes nos trabalhos de Goldthorpe e Marshall (1992) e Ekehammar, Sidanius e Nilsson (1987) para definir objetivamente os critérios sobre o que seria classe social, algo bastante análogo à definição de classe de E11.

\begin{abstract}
Eu acho que classe social define o carro que ele anda, a roupa que ele veste, a casa que ele mora. Acho o que define a classe social é isso aí. E se eu pago aluguel e moro em um bairro da periferia eu acho que minha classe social é mais inferior e a pessoa que mora num bairro em que 0 metro quadrado é mais caro. Isso aí define a classe social das pessoas que moram lá. (E11, Pobre)
\end{abstract}

Além de utilizarem elementos objetivos estabelecidos pelos trabalhos de Goldthorpe e Marshall (1992) e Ekehammar, Sidanius e Nilsson (1987) para definição de classe, E9 e E11 acrescentam outros elementos objetivos, tais como o local da moradia e consumo como componentes objetivos definidores de classe social no contexto brasileiro. Dentro dessa definição fundamentada em critérios objetivos, os alunos acreditam que classe social sempre é considerada como coletivamente coesa, categórica, oposicional e auto excludente (Bottero, 2004), por meio da qual indivíduos objetivamente classificados em uma classe social não podem pertencer a outras classes ou ter comportamentos ou características consideradas de outras classes sociais, pois os elementos objetivos seriam critérios autossuficientes na definição da classe social (Kelley \& Evans, 1995). Neste sentido, aspectos socioeconômicos seriam suficientes para produzir diferenças subjetivas cruciais e marcantes entre indivíduos de classes sociais diferentes (Sales, 2014), uma vez que as separações de classe são baseadas e centralizadas em processos econômicos de produção e consumo (Yuval-Davis, 2006).

Entretanto, os alunos que participaram das entrevistas também manifestaram um entendimento de classe que rompe com essa lógica oposicional, coesa e auto excludente fundamentada apenas em aspectos socioeconômicos como definidores centrais de classe social, o que demonstra o antagonismo e as incompletudes dos critérios relacionados à renda, moradia, ocupação e consumo na definição de classe: "Você tem tipo assim um item que se destaca socialmente. Por exemplo, celular. Um monte de pessoa paga 3.000 reais num celular, só que você vai em casa a luz está cortada, não tem água" (E17, Média). Esse antagonismo presente no discurso de E17 (Média) exemplifica a incompletude na definição de classe apenas por elementos objetivos. Tais antagonismos e incompletudes são evidenciados pela classe subjetiva, que será analisada a seguir. 
Classe subjetiva: uma perspectiva multifacetada

A identificação dos indivíduos em uma determinada classe nem sempre é uma tarefa simples, oposicional e coesa. Indivíduos classificados por critérios objetivos como pertencentes a uma classe podem não se identificar e não se reconhecer na classe objetiva na qual são classificados. Sempre existirá um espaço para divergências entre aspectos objetivos e subjetivos, marcando uma discrepância entre elementos subjetivos relacionados ao estilo de vida, auto identificação, formas de lazer, atitudes políticas e características socioeconômicas objetivas (Haddon, 2015). Isso torna o processo de classificação social complexo, ambivalente e opaco (Irwin, 2015).

Eu vejo como a condição financeira, o lugar que você tem na sociedade. Tipo a gente é pobre, mas sou filho de um político importante. Minha condição social vai ser mais elevada que uma pessoa que pode até ter mais dinheiro que eu [...]. (E17, Média)

E17 exemplifica porque a abordagem culturalista sobre classe social tece críticas à definição puramente objetiva de classe, ao afirmar que o prestígio social do cargo que seu pai ocupa lhe garante acesso a uma classe superior que the seria atribuída, se fossem considerados apenas aspectos econômicos na definição de sua classe, pois acredita que sua classe não está limitada e exclusivamente definida por aspectos como renda, consumo e trabalho. Para a abordagem culturalista, a classe objetiva não captura elementos culturais e sociais que estão para além do econômico. Entretanto, tais elementos interferem no processo de construção das identidades de classe (Savage et al., 2013). No caso de E17 ser filho de um político, esse é um aspecto cultural e social mais relevante no contexto brasileiro do que a renda e condição financeira. Assim, classe social é também um processo de "Diferenciação cultural e social" (E35, Média) e não um processo meramente econômico. Muitos alunos entendem classe como algo "mais estilo de vida mesmo" (E38, Média), atribuindo ao estilo de vida e aos aspectos culturais elementos constituintes de suas identidades de classe, ao invés de somente aspectos econômicos: "Estilo de vida. Às vezes a pessoa pode até não ganhar tanto, mas ela vive um estilo de vida de uma classe social diferente da dela" (E32, Média). Esse processo de desidentificação em relação à classe objetiva e de identificação de uma classe subjetiva podem ser evidenciados na afirmação abaixo:

Classe média também e por questões de hábitos, os lugares frequentados e a questão do poder aquisitivo também, a faixa de preço das coisas que você compra, os lugares que frequenta que te encaixam numa classe social. (E32, Média)

Portanto, classe social é um aspecto multifacetado, plural e não determinado apenas por aspectos objetivos (Crompton, 1998; Bottero, 2004). E32 se identifica como classe média não somente pelo seu poder aquisitivo ou consumo, mas principalmente por seus hábitos sociais e culturais associados aos lugares que frequenta, assim como seus hábitos. Além disso, também considera como elementos constituidores de classe social aspectos relacionados aos processos culturais, que por sua vez são embebidos em práticas sociais, sem desconsiderar aspectos econômicos nessa análise (Devine \& Savage, 2000; Devine, 1998). Sendo assim, isso demonstra os 
micro processos sociais que constituem classe em um determinado espaço e tempo (Devine, 1998), manifestando a característica multifacetada, implícita, contextual e subjetiva dos processos de identificação de classe (Bottero, 2004). Portanto, a classe subjetiva produz igualdade e diferença, pois o indivíduo declara igualdade e diferença em relação às classes sociais que se apresentam como possibilidades de existência identitária de classe, conforme pode ser visto a seguir:

Eu sou da periferia, mas estou na minha segunda graduação. Não é comum na região onde eu moro. As pessoas têm fundamental até o médio. [...]. Nem todo mundo passou por aqui ou fez faculdade particular, por exemplo. Eu moro na favela, mas a favela não mora em mim! (E31, Média)

E31 considera que apesar de morar em uma favela o mesmo não se identifica como sendo pertencente à classe social baixa. É exatamente a possibilidade de estudar em uma universidade federal que o faz se desidentificar como parte do seu contexto e se identificar como pertencente à classe social superior aos demais residentes de seu bairro. Apesar da declaração de igualdade em relação aos seus vizinhos, por dizer que mora no mesmo bairro que eles, o fato de estudar em universidade federal faz com que se sinta diferenciado em relação aos demais moradores da favela, afirmando inclusive que a favela não mora nele. Portanto, devido aos alunos identificarem-se e desidentificarem-se simultaneamente a uma mesma classe social faz com que as identidades produzidas se tornem heterogêneas e não coesas, contribuindo com que os indivíduos não mais se reconhecem em identidades de classe que representem grupos discretos, objetivos e distintos. Isso obscurece as fronteiras e limites entre as classes, tornando classe algo implícito e subjetivo, ao invés de algo meramente objetivo (Bottero, 2004). Ademais, produz identidades coletivas de classe não coesa, pela qual a classe é definida muito mais como um processo de diferenciação do que uma identidade coletiva coesa, homogênea e unitária (Savage, 2000).

Considerar classe como subjetiva não significa abandonar aspectos econômicos na definição de classe, mas representa que o econômico não deve ser considerado como elemento determinante na definição de classe, pois classe não é algo tão claro, explícito e objetivo para os sujeitos (Reay, 1998). É, na verdade, um processo sutil, individual e implícito de hierarquização (Bottero, 2004), que demonstra que os processos sociais que estruturam classe são tanto objetivos quanto subjetivos. Vale ressaltar que esse processo sutil de produção de identidades individuais de classe em detrimento das identidades de classe coletivas coesas e homogêneas é mediado pelas comparações que os indivíduos realizam de si mesmos com outros sujeitos de diferentes classes sociais.

\section{É uma correlação a questão do acesso que você tem. Se você tem acesso a determinadas coisas. Você querendo ou não, você comparar, você fazer comparativo é do ser humano, você querendo ou não você acaba fazendo. (E30, Média)}

As comparações sociais fazem com que as percepções dos sujeitos em relação à classe que pertençam sejam mais flexíveis (Bottero, 2004; Irwin, 2015; Runciman, 1966). Isso se intensifica muito mais em sociedades relacionais, como a sociedade brasileira. Devido a isso, E2 (Média) define 
classe social como "[...] as pessoas que você se relaciona". O discurso de E2 manifesta a importância do elemento relacional na constituição da classe social subjetiva. As pessoas com quem você se relaciona é algo extremamente importante em sociedades relacionais como a brasileira (DaMatta, 1978). Aliás, a importância das relações interpessoais na definição de classe no contexto brasileiro coaduna com a importância que a abordagem cultural dá a relações entre sujeitos, ao definir classe como algo relacional (Bottero, 2004, 2012; Marshall \& Swift, 1996; Runciman, 1966). Contudo, a especificidade do contexto brasileiro demonstra que a classe é relacional não somente porque é construída por meio de comparações que o indivíduo faz em relação aos seus pares. Na verdade, os indivíduos fazem essas comparações para se identificarem em termos de classe social. Contudo, classe também é relacional, porque as oportunidades que o indivíduo tem também são delimitadas pelas relações interpessoais com membros de classes sociais superiores. Quanto mais estreitas essas relações, maiores as oportunidades econômicas, sociais e culturais que os indivíduos terão.

Por fim, a constante realização de comparações faz com que o indivíduo se classifique como classe média, pois tende a considerar como se estivesse no meio em termos de classe social, por acreditar que seu estilo de vida e das pessoas com quem se compara são muito próximas (Bottero, 2012; Evans \& Kelley, 2004; Irwin, 2015). Isso explica porque durante a realização das entrevistas 35 alunos dos 38 que participaram da pesquisa se auto declaram como pertencentes à classe média, enquanto apenas 3 afirmaram que são pobres.

\section{Conclusão}

Este artigo buscou analisar se classe social é um marcador social no cntexto brasileiro e, caso fosse, como os alunos de graduação do curso de administração de uma universidade federal definem classe. Como pode ser verificado durante as análises dos dados produzidos, classe é um marcador social relevante que produz desigualdades sociais, econômicas, culturais e educacionais. Os alunos atribuem uma grande importância à classe social nas práticas cotidianas contemporâneas, definindo classe social como um grupo coeso, além de visualizarem as fronteiras e classificações, mesmo que turvas e subjetivas, considerando que classe é um marcador social no contexto brasileiro e que não está morto. Desta forma, atua como organizador social, confirmando a estratificação e, consequentemente, a pouca distribuição de influência social entre classes diferentes e a existência de desigualdades laborais, sociais, culturais e educacionais em função de classe. Desta forma, os alunos dão importância à classe social como marcador e enxergam a existência de fronteiras de classe, atuando na hierarquização dos indivíduos, bem como reconhecerem a relevância de classe na construção identitária e na produção de desigualdades sociais.

Os alunos de administração definem classe tanto por critérios objetivos quanto subjetivos, valorizando aspectos objetivos e subjetivos na definição de classe. A importância de critérios objetivos relacionados aos elementos 
econômicos na definição de classe subjetiva manifesta a relevância de classe em sociedades menos desenvolvidas, fato que revela o alto nível de estratificação social na sociedade brasileira em termos de distribuição de renda. Em outras palavras, as desigualdades sociais e econômicas estão presentes na sociedade brasileira, fazendo com que o estado brasileiro não se categorize como um welfare-state e que classe não morreu, pelo contrário. Além disso, os alunos declaram um processo de classe multifacetado, plural e não determinado pelo econômico, definindo classe por meio de processos embebidos em práticas sociais e aspectos econômicos, enfatizando os micro processos sociais que constituem classe no contexto brasileiro e afirmando critérios implícitos, contextuais e subjetivos nos processos de identificação de classe.

Assim, este artigo pretendeu contribuir com os estudos organizacionais ao abordar questões sobre classe, promovendo o debate sobre o tema e, assim, reduzir a carência contemporânea de estudos sobre classe na área. Além disso, a abordagem culturalista de classe ainda é pouco explorada pelos estudos organizacionais brasileiros e este artigo visa trazer para o campo o debate dessa perspectiva, cobrindo também esta lacuna. Considerando que o curso de administração visa formar gestores que serão responsáveis pelo desenvolvimento de políticas públicas e privadas relacionadas à diversidade e diferenças, entender como os alunos de administração atribuem relevância à classe social e a significam é uma tarefa importante, pois permite estabelecer um diagnóstico sobre o tema, além de designar direções na formação dos mesmos, para que os alunos possam ser capacitados como gestores e também sejam sensibilizados para desenvolverem políticas públicas e privadas focadas em desigualdades de classe no contexto do trabalho.

Como limitador do estudo destaca que o período em que os dados foram produzidos, sendo durante a crise econômica brasileira (2015-2016), fato que pode ter influenciado e direcionado a definição de classe pelos alunos em termos econômicos. Em relação às futuras pesquisas, é necessário o desenvolvimento de estudos sobre classe social na área de administração, principalmente a aplicação do modelo de classe que traga capitais econômicos, sociais e culturais na definição de classe, denominado de Análise de Classe Cultural. O modelo de Análise de Classe Cultural é um modelo multidimensional fundamentado nos três capitais que promovem vantagens sociais, definidos por Bourdieu (1984) para registrar as diferenciações de classe social. São eles: capital econômico (riqueza e renda); capital cultural (engajamento em bens culturais e credenciais institucionalizadas obtidas através de nível educacional em instituições educacionais reconhecidas como superiores) e capital social (redes de relacionamento pessoais e conexões sociais). Além disso, necessitam ser desenvolvidas pesquisas culturalistas sobre classe nas organizações, de modo a buscar compreender como classe atua como produtor de diferenças no trabalho. Sendo assim, é importante analisar principalmente como a formação em administração de gestores organizacionais impacta na forma em que os mesmos enxergam classe como um produtor de diferença no ambiente organizacional e como essa diferença impacta na promoção e crescimento dos trabalhadores para ocuparem cargos de gestão e direção. 


\section{Referências}

Acker, J. (1999). Rewriting class, race, and gender: problems in feminist rethinking. In M. M. Ferree, J. Lorber, \& B. B. Hess (Eds). Revisioning gender. Thousand Oaks: Sage.

Acker, J. (2006). Inequality regimes gender, class, and race in organizations. Gender \& Society, 20(4), 441-464.

Acker, J. (2011). Theorizing gender, race and class in organizations. In: E. Jeanes, D. Knights, \& P. Y. Martin (Eds.). Handbook of Gender, Work and Organization (pp. 65-80). West Sussex: Wiley-Blackwell.

Andersen, R., \& Curtis, J. (2012). The polarizing effect of economic inequality on class identification: evidence from 44 countries. Research in Social Stratification and Mobility, 30(1), 129-141.

Atkinson, W. (2007). Beck, individualization and the death of class: a critique. The British Journal of Sociology, 58(3), 349-366.

Bardin, L. (2009). Análise de Conteúdo. Lisboa: Edições 70.

Baumann, Z. (1992). Intimations of Postmodernity. London e New York: Routledge.

Beck, U., \& Lau, C. (2005). Second modernity as a research agenda: theorical and empirical explorations in the 'metachange' of modernity. The British Journal of Sociology, 56(4), 525-557.

Beck, U. (1992). Risk Society: Toward a New Modernity. London: Sage.

Beck, U. (1994). The reinvention of politics: towards a theory of reflexive modernization. In U. Beck, A. Giddens, \& S. Lash, Reflexive Modernization: Politics, Tradition and Aesthetics in the Modern Order (pp. 1-55). Cambridge: Polity Press.

Beck, U. (1995). Ecological Politics in an Age of Risk. Cambridge: Polity Press.

Beck, U. 1997 The Reinvention of Politics: Rethinking Modernity in the Global Social Order. Cambridge: Polity Press.

Beck, U. (2000). The cosmopolitan perspective: sociology of the second age of modernity. The British Journal of Sociology, 51(1), 79-105.

Beck, U., \& Beck-Gernsheim, E. (2002). Individualization: institutionalized individualism and its social and political consequences. London: Sage.

Beck, U., \& Willms, J. (2004). Conversationswith Ulrich Beck. Cambridge: Polity Press.

Bottero, W. (2004). Class identities and the identity of class. Sociology, 38(5), 9851003.

Bottero, W. (2005). Social stratification and inequality. London: Routledge.

Bottero, W. (2012). Who do you think they were? How family historians make sense of social position and inequality in the past. The British Journal of Sociology, 63(1), 54-74.

Bourdieu, P. (1984). Distinction. London: Routledge.

Braverman, H. (1974). Labour and Monopoly Capital: The Degradation of Work in the Twentieth Century. New York e London: Monthly Review Press. 
Calás, M. B., \& Smircich, L. (1996). Thematic editorial on gender, race, class and organization. Organization, 3(4), 459-60.

Centers, R. (1949). The Psychology of Social Classes: A Study of Class Consciousness. Princeton: Princeton University Press.

Crompton, R. (1996). The fragmentation of class analysis. British Journal of Sociology, 47(1), 56-67.

Crompton, R. (1998). Class and Stratification. Cambridge: Polity.

DaMatta, R. (1978). Carnavais, Malandros e Heróis: Para uma Sociologia do Dilema Brasileiro. Rio de Janeiro: Rocco.

Devine, F., \& Savage, M. (2000). Conclusion: renewing class analysis. In: R. Crompton, F. Devine, M. Savage, \& J. Scott (Eds). Renewing Class Analysis (pp. 184-199). Oxford: Blackwell.

Devine, F. (1998). Class analysis and stability of class relations. Sociology, 32(1), 23-42.

Devine, F. (2004). Class Practices. Cambridge: Cambridge University Press.

Edlund, J. (2003). The influence of the class situations of husbands and wives on class identity, party preference and attitudes towards redistribution: Sweden, Germany and the United States. Acta Sociologica, 46(3), 195-214.

Ekehammar, B., Sidanius, J., \& Nilsson, I. (1987). 'Social Status: construct and external validity'. Journal of Social Psychology, 127(5), 473-481.

Evans, M. D. R., \& Kelley, J. (2004). Subjective social location: data from 21 nations. International Journal of Public Opinion Research, 16(1), 3-38.

Evans, G., \& Tilley, J. (2012). How parties shape class politics: explaining the decline of the classes basis of party support. British Journal of Political Science, 42(1), 137-161.

Goldthorpe, J., \& Marshall, G. (1992). The promising future of class analysis. Sociology, 26(3), 381-400.

Goldthorpe, J. (1996). Class analysis and the reorientation of class theory. British Journal of Sociology, 47(3), 481-505.

Haddon, E. (2015). Class identification in New Zealand: an analysis of the relationship between class position and subjective social location. Journal of Sociology, 51(3), 737-754.

Harding, N., Ford, J., \& Fotaki, M. (2013). Invited contribution 'Is 'F' word still dirty? Twenty years of feminism and gender studies in Organization and feminist journals', Organization, 20(1), 51-65.

Holvino, E. (1994). Women of color in organizations: revising our models of gender at work. In: E. Y. Cross, J. H. Katz, F. A. Miller, \& E. W. Seashore (Eds) The Promise of Diversity (pp. 52-59). Burr Ridge: Irwin Professional Publishing.

Holvino, E. (1996). Reading organization development from the margins: outsider within. Organization, 3(4), 520-533.

Holvino, E. (2010). Intersections: the simultaneity of race, gender and class in organization studies. Gender, Work and Organization, 17(3), 248-277.

Irwin, S. (2015). Class and comparison: subjective social location and lay experiences of constraint and mobility. The British Journal of Sociology, 66 (2), 259-281. 
Law, J. (1992). Notes on the theory of the actor-network: ordering, strategy and heterogeneity. Systems Practice, 5(4), 379-393.

Kelley, J., \& Evans, M.D.R. (1995) 'Class and class conflict in six western nations', American Sociological Review, 60, 157-178.

Marshall, G., \& Swift, A. (1996). Merit and mobility? A reply to Peter Saunders. Sociology, 30 (2), 375-386.

Marx, K. (1992). Capital: critique of political economy. Harmondsworth: Penguin Books.

Munro, A. (2001). A feminist trade union agenda? The continued significance of class, gender and race. Gender, Work \& Organization, 8 (4), 454-471.

Reay, D. (1998). Rethinking social class: qualitative perspectives on class and gender. Sociology, 32 (2), 259-275.

Runciman, W. G. (1966). Relative deprivation and social justice. London: Routledge.

Saffioti, H. (2009). Ontogênese e filogênese do gênero: ordem patriarcal de gênero e a violência masculina contra mulheres. Série Estudos/ Ciências Sociais/ FLASCOBrasil. 2009. Recuperado em 09 maio, 2016, de http://flacso.redelivre.org.br/ files/2015/03/Heleieth_Saffioti.pdf

Sales, M. S. (2014). O processo de constituição da identidade na adolescência: trabalho, classe e gênero. Psicologia \& Sociedade, 26, 161-171.

Savage, M. (2000). Class analysis and social transformation. Oxford: Oxford University Press.

Savage, M., Devine, F., Cunningham, N., Taylor, M., Li, Y., Hjellbrekke, J., Roux, B., Friedman, S., \& Miles, A. (2013). A new model of social class? Findings form the BBC's Great British Class Survey Experiment. Sociology, 47(2), 219-250.

Scully, M. A., \& Blake-Beard, S. (2006). Locating class in organizational diversity work: class as structure, style and process. In: A. M. Konrad, P. Prasad, \& J. K. Pringle (Eds.). Handbook of Workplace Diversity (pp. 431-454). London: SAGE Publications.

Skeggs, B. (2004). Class, self, culture. London: Routledge.

Silveira, R. S., \& Nardi, H. C. (2014). Interseccionalidade gênero, raça e etnia e a lei Maria da Penha. Psicologia \& Sociedade, 26, 14-24.

Spivak, G. C. (1998). Can the subaltern speak? In: C. Nelson, \& L. Grossberg (Eds.). Marxism and the Interpretation of Culture (pp. 271-316). Urbana: University of Illinois Press.

Wasserman V., \& Frenkel, M. (2015). Spatial work in between glass ceilings and glass walls: gender-class intersectionality and organization aesthetics. Organization Studies, 36(11), 1485-1505.

Weber, M. (1978). Economy and society. Berkeley: University of California Press.

Yuval-Davis, N. (2006). Intersectionality and Feminist Politics. European Journal of Women's Studies, 13(3), 193-209. 